\title{
Status, Distribution and Parasitism Rate of Olive Fruit Fly (Bactrocera oleae.Rossi) Natural Enemies in Lebanon
}

\author{
Abdel Kader El-hajj (Corresponding author)
}

Lebaa Station, Lebanese Agricultural Research Institute (LARI), P.O. Box 90-1965, Fanar, Jdeideh, El Metn, Lebanon. Tel: 961-7-230-014. E-mail: ak.hajj@lari.gov.lb

\section{Nabil Nemer}

Holy spirit university of Kaslik, Faculty of agricultural and food science, Lebanon.

\section{Samer Hajj Chhadeh}

Saint Joseph's University, Lebanon.

\section{Faten Dandashi}

Abdeh station, Lebanese Agricultural Research Institute, Abdeh, Lebanon.

Hiyam Yosef \& Mouhammed Nasrallah

Tyre station, Lebanese Agricultural Research Institute, Tyre,Lebanon.

Mayssaa Houssein, Vera Talj \& Mahmoud Haris

Lebaa station, Lebanese Agricultural Research Institute, Lebaa, Lebanon.

\section{Zinnet Moussa}

Entomology department, Lebanese Agricultural Research Institute, Fanar, Lebanon,

Received: January 2, 2018

doi:10.5296/jas.v6i1.12769
Accepted: February 7, 2018

URL: https://doi.org/10.5296/jas.v6i1.12769 


\begin{abstract}
Olive tree is considered one of the most important cultivated crops in Lebanon. The cultivated area is mainly concentrated in the north and south Lebanon. Among the obstacles affecting olive cultivation is the olive fruit fly infestation which negatively alters the quality of olive oil. Olive fruit fly (Bactrocera oleae) is mainly controlled by chemical means. At the present time, no biological program against this pest is considered in Lebanon. The aim of this study is to investigate the status of olive fruit fly parasites in Lebanon. The study was conducted for one year in 28 orchards located in five regions of olive production. Fruit samples were collected weekly from June to October. A total of 23096 fruits was collected from all orchards. Eight parasites were detected. Eupelmus urozonous and Opius concolor were the most abundant parasites in most orchards, the others were restricted to specific locations. The only exception was observed at Abdeh site where most of the parasites were isolated. Parasitism rates ranged from 2.4 to $42.1 \%$ and the average rate of all locations was $13.3 \%$. The low parasitism rate recorded in this study is insufficient to control olive fruit fly. Introduction and rearing of natural enemies along with other management tactics may enhance the control of olive fruit fly infestation
\end{abstract}

Keyword: Olive tree, B.oleae,E.urozonus,O.concolor. Parasite, Parasitism rate.

\title{
1. Introduction
}

Olive tree is considered one of the most important cultivated crops in Lebanon. It represents about $43 \%$ of the cultivated area with fruit trees (FAO, 2012). The main cultivated area with olive trees is concentrated in the North and South Lebanon. In Mount Lebanon olive trees are mainly grown in Chouf region (FAO, 2012). The fruit infestation by B.oleae (Rossi) (Diptera: Tephritidae) is the main threat affecting olive cultivation in Lebanon. The adult females deposit their eggs ( 50-400 eggs in her lifetime) under the skin of the fruit(Daniela Merchini et al.,2017). The Larvae develop and feed on the pulp of the fruit. Infested fruits often drop prematurely. Secondary infestation of bacteria and fungi accumulated in the tunnels made by the larva inside the fruits decreases oil quality (F. G. Zalom, et.al,2003).

Chemical pesticide is the main option used to control olive fruit fly. Other option like attract and kill devices that minimize the impact of full cover spraying may offer an alternative management method to the use of synthetic pesticides (Iannotta N. et al,. 2010). Biological programs are scarce despite the existing of some parasites of B. oleae. In Lebanon, little information about parasitoid fauna is reported .Currently, no biological program against this pest is considered in Lebanon. E. Mechelany (1969) reported in his study five parasitoids( Opius cocolor Szepl., Eupelmus Urozonus Dalm., Cyrtoptyx dacicida Masi., Pnigalio mediterraneus Del., Eurytoma rosa (Nees.)) to be present in Lebanon. The first two of them are the most common.

O. Concolor and other parasitoids of the Bracinoid family are reported to be native to Africa (Biliotti, E. 1961, Cameron, E. 1941, Fischer, M. 1963). They were introduced to Europe (Fischer, M. 1963, Tobias, V. I. 1977, Monaco R. 1978), Jordan (Mustafa T. M. and Al-Zaghal K. 1987), Lebanon (Brnetic D. and Domazet D. 1981) and to other countries. 
Four chalcidoid wasps were reported to be present in southern Europe E. urozonus (Hym.: Eupelmidae), P. mediterraneus (Hym.: Eulophidae), Cyrtoptyx latipes (Rondani) (Hym.: Pteromalidae) and Eurytoma martellii Domenichini (Hym.: Eurytomidae). Many of chalcidoid species are not specific to olive fruit fly and they attack unrelated hosts in several different insect orders mostly the family of tephritidae (Kim A. Hoelmer et al.,2011)

The objective of this study is to investigate the status, distribution and parasitism rate of olive fruit fly natural enemies in Lebanon for potential developing of future bio-control programs.

\section{Methods and Material}

The study was carried out for one year (2014) in 28 olive orchards located in five regions(Tyre,Nabatieh,Saida-Jizzin,Chouf,North). These orchards are mainly planted with local Baladi variety except for Abdeh orchard(North) which was planted with various local and imported varieties. The orchards are located along the littoral and up $850 \mathrm{~m}$ above sea level. The fruit sampling began in June and continued until the end of October. The fruits were kept in aerated transparent plastic boxes under ambient lab temperature for one month. The emergence of fruit fly and parasites were recorded every 2-3 days. Parasitism rate was calculated by the following formula: $100 \mathrm{xP} /(\mathrm{P}+\mathrm{F})$, where $(\mathrm{p})$ the total number of emerged parasites ; $(\mathrm{F})$ the number of olive fruit flies. In addition to pheromone traps ,McPhail traps baited with a $3 \%$ of diammonium sulfate solution were placed in each orchard for monitoring the dynamics of olive fruit fly. The level of infestation by B.oleae was recorded on a sample of 100 fruits from each orchard at four dates. Parasite species were identified at the Lebanese agricultural research institute (entomology department). Statistical analysis was performed by using SAS for windows V8. A ttest was performed to discriminate between the means of captured flies on both pheromone and McPhail traps, female and male of B.oleae and O.concolor and E.urozonus. Analysis of variance was performed to test the variation in the number of parasites and captured flies by locations and regions.

\section{Results and Discussion}

The captured flies on both McPhail and pheromone traps revealed a widespread of B.oleae throughout all selected regions(Table1). This can be explained by an assumption of the association of olive tree with $B$. oleae which was considered an indigenous to the Mediterranean basin (Kim A. Hoelmer et al.,2011). Captured flies on McPhail traps $(M=32.8, S D=29.4)$ were significantly higher than on pheromone traps $(M=13.2, S D=17.3)$, $F(1)=9.66, p<.0001$. The number of flies differed significantly between regions on both McPhail and pheromone traps respectively $F(5,284)=6.2, \quad p<.0001, F(5,276)=12.6$, $p<.0001$.The highest number of flies was observed in Tyre, Middle and coastal Chouf regions (Table1).Male and female flies were counted on McPhail traps and the results showed that male flies( $\mathrm{M}=19.5, \mathrm{SD}=18.1) \quad$ were significantly higher than female $(M=11.5, S D=11.6), \mathrm{t}(1)=2.3, p<.0001$. 


\section{Macrothink}

Journal of Agricultural Studies

ISSN 2166-0379

2018, Vol. 6, No. 1

Table1.Average number of B.oleae adults captured on pheromone and McPhail traps from four regions during 2014.

\begin{tabular}{|c|c|c|c|c|}
\hline \multirow[t]{2}{*}{ Region } & \multirow[t]{2}{*}{ Pheromone trap } & \multicolumn{3}{|c|}{ McPhail trap (Diammonium sulphate, $3 \%$ ) } \\
\hline & & Total & male & female \\
\hline \multicolumn{5}{|l|}{ Chouf } \\
\hline High & $7.7(12.0) b$ & $22.9(23.6) b$ & 11.9(11.7)d & $8.0(8.1) b c$ \\
\hline Middle & 19.1(17.8)a & 44.7(29.3)a & 29.4(20.3)ab & $13.6(12.4) \mathrm{b}$ \\
\hline Coastal & $21.4(23.5) \mathrm{a}$ & $50(36.5) \mathrm{a}$ & $32.4(25.6) \mathrm{a}$ & $13.1(8.9) b$ \\
\hline Jizzin-Saida & $12.3(20.6) \mathrm{a}$ & $28.6(24.2) \mathrm{b}$ & $17.7(15) \mathrm{dc}$ & $11(9.8) b c$ \\
\hline Nabatieh & $7.7(5.2) \mathrm{b}$ & $17.4(12.1) \mathrm{b}$ & $11.2(8.1) \mathrm{d}$ & $6.2(4.5) \mathrm{c}$ \\
\hline Tyre & 17(11.9)a & $50.6(37.1) \mathrm{a}$ & $22.6(16) b c$ & $28(22.4) \mathrm{a}$ \\
\hline
\end{tabular}

Note. Columns with different letters are significantly different (Tukey's test, $p<0.05$ ).

Eight parasitoids and one predator were recorded in this study: Opius concolor (Hymenoptera, Braconidae), Eupelmus urozonus (Hymenoptera Chalcidoidea), Cyrtoptyx dacicida (Hymenoptera, Pteromalidae), Pnigalio mediterraneus Del (Hymenoptera, Eulophidae), Eurytoma spp. (Hymenoptera, Eurytomidae), Tetrastichus sp. (Hymenoptera, Eulophidae), Pteromalus (Hymenoptera:Pteromalidae), Bracon sp.,(Hymenoptera,Braconidae) (Fig.1), and Prolasioptera berlesiana Paoli (Diptera, Cecidomyiidae ). The first five were mentioned by Mechalany 1969 to be parasitoids of olive fruit fly in Lebanon.

Five parasitoids were isolated from olive fruit samples collected from Abdeh olive germplasm ( North Lebanon)(Table2) where E.urozonus was the most common parasitoid. Tetrastachus sp.has been already reported to be a parasitoid of B.oleae in Jordan(Mustafa and Al- Zaghal 1987).Tetrastachus sp. has been reported to be present in Lebanon (M.Khouzami et al.,1996) but there is no information about this species as a parasitoid of B.oleae. It should 


\section{Macrothink}

Journal of Agricultural Studies ISSN 2166-0379 2018, Vol. 6, No. 1

also be noted that there have been no reports about parasitism action of Bracon sp. and Pterolamus $s p$ which were isolated from two olive fruit samples on olive fruit fly in Lebanon

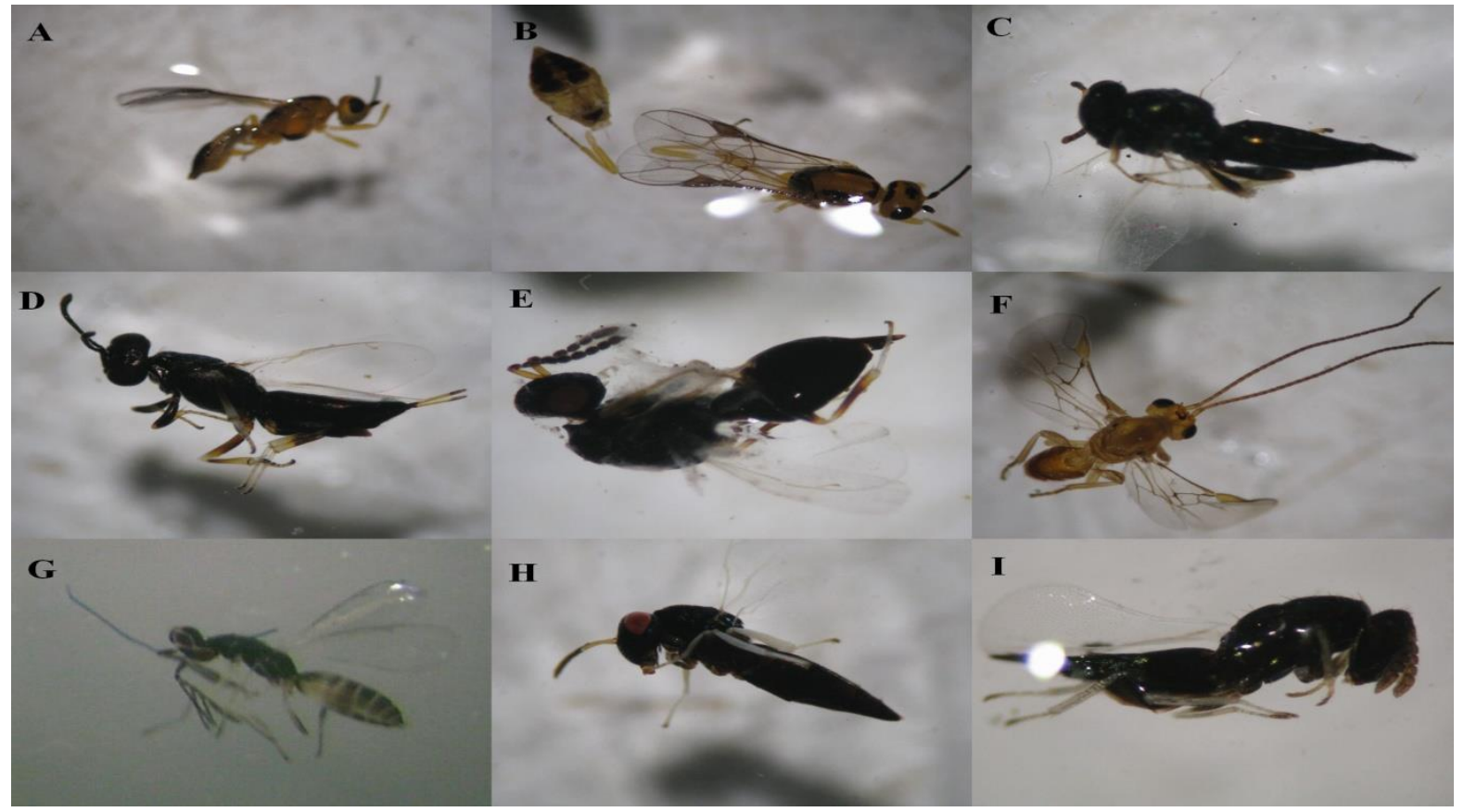

Figrue1.Isolated parasitoids from olive fruit samples: (A) (B) Bracon sp.,(C) ) Cyrtoptyx dacicida,(D) Eupelmus urozonus,(E) Eurytoma spp., (F) O.concolor,(G) Pnigalio meditterranean (H) Pteromalus, (I) Tetrastichus sp 


\section{Macrothink}

Results showed a wide distribution of E.urozonus throughout all orchards. E.urozonus was caught from July till the mid of September (Table3).

In high elevation zone of Chouf region (Hasrout), E.Urozonus was recorded in the third week of October(Table3). It was also noticed a wide spread of O.Concolor in most orchards .The exception was observed in Sfarey (Jizzin region), Bazurieh and Aita al-Shaab(Tyre region) orchards where O.concolor was not recorded. Their activity was observed from-summer and continued until the third week of November (Table 3).Both species parasite third instar larvae, and can also parasite first and second instar. The other recorded parasitoids were rare and restricted to specific locations

Although the total number of E.urozonus was higher than the number of O.concolor, a ttest showed no significant difference between them (E.urozonus $(M=7.3, S D=11.1)$, O.concolor $(M=4.6, S D=4.4)$ and,$(F(1)=-1.13, p=0.265))$. 
Table2: The distribution of 8 parasites isolated from olive fruit samples over the orchards of olive cultivation.

\begin{tabular}{|c|c|c|c|c|c|c|c|}
\hline $\begin{array}{l}0 \\
\stackrel{0}{0} \\
\stackrel{0}{0} \\
\stackrel{0}{\circ}\end{array}$ & 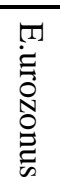 & 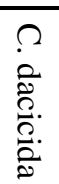 & 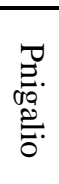 & 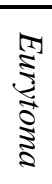 & 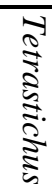 & 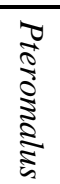 & 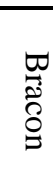 \\
\hline
\end{tabular}

Chouf

High elevation zone

$\begin{array}{lll}\text { mmatour MLC1 } & + & + \\ \text { Atrin MLC2 } & + & + \\ \text { Baaklin MLC3 } & + & + \\ \text { Hasrout MLC4 } & & + \\ \text { Moukhtara MLC5 } & & +\end{array}$

Middle elevation zone

Debieh MLC1

Chhim MLC2

Joun MLC3

Kfarfakoud MLC4

Bourjein MLC5

Coastal zone

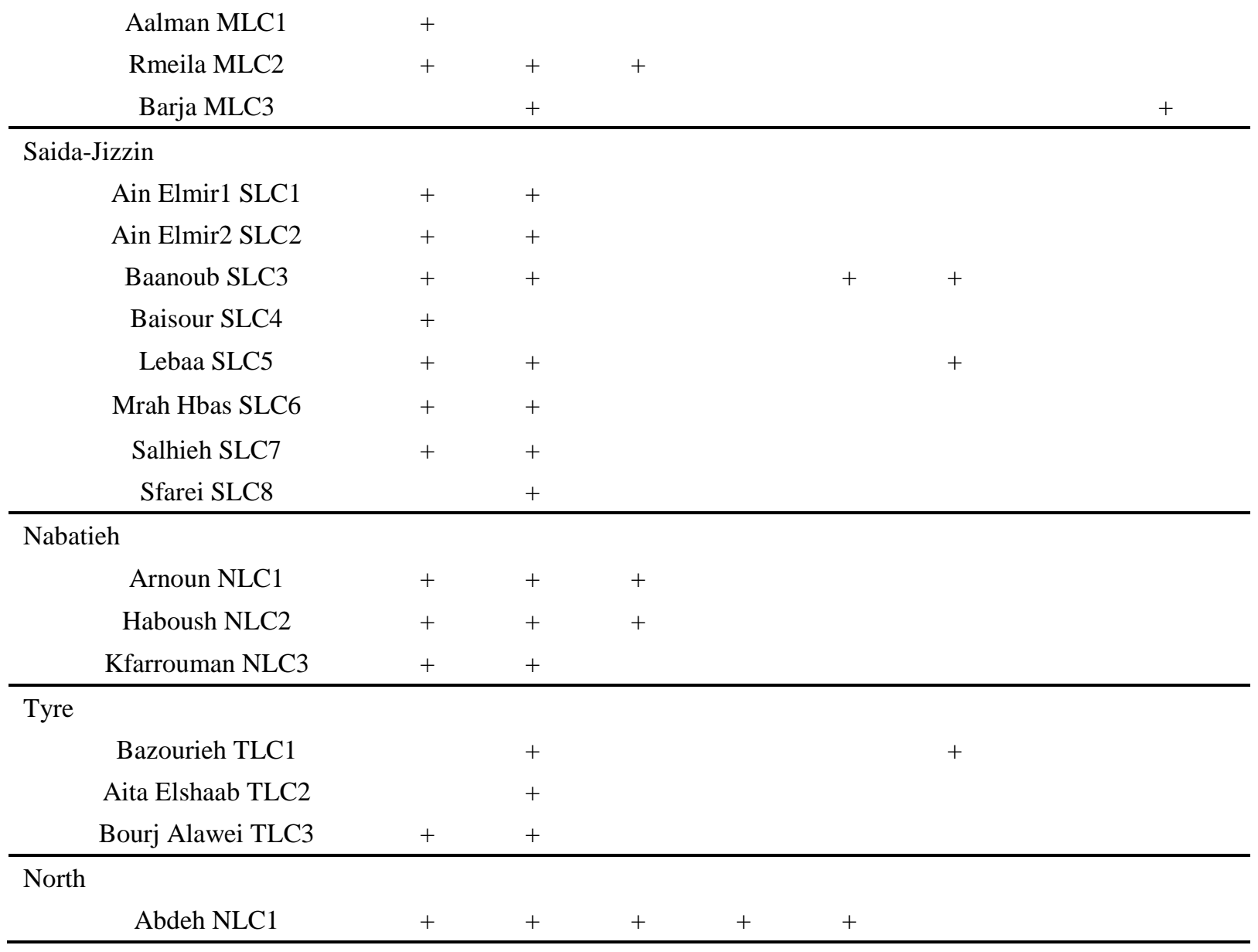




\section{Macrothink}

Journal of Agricultural Studies

ISSN 2166-0379

2018, Vol. 6, No. 1

Table3.Dynamics and distribution of two parasitoids (O.concolor and E.urozonus) in Chouf,

Saida-Jizzin, Nabatieh, Sour and Abdeh regions-2014

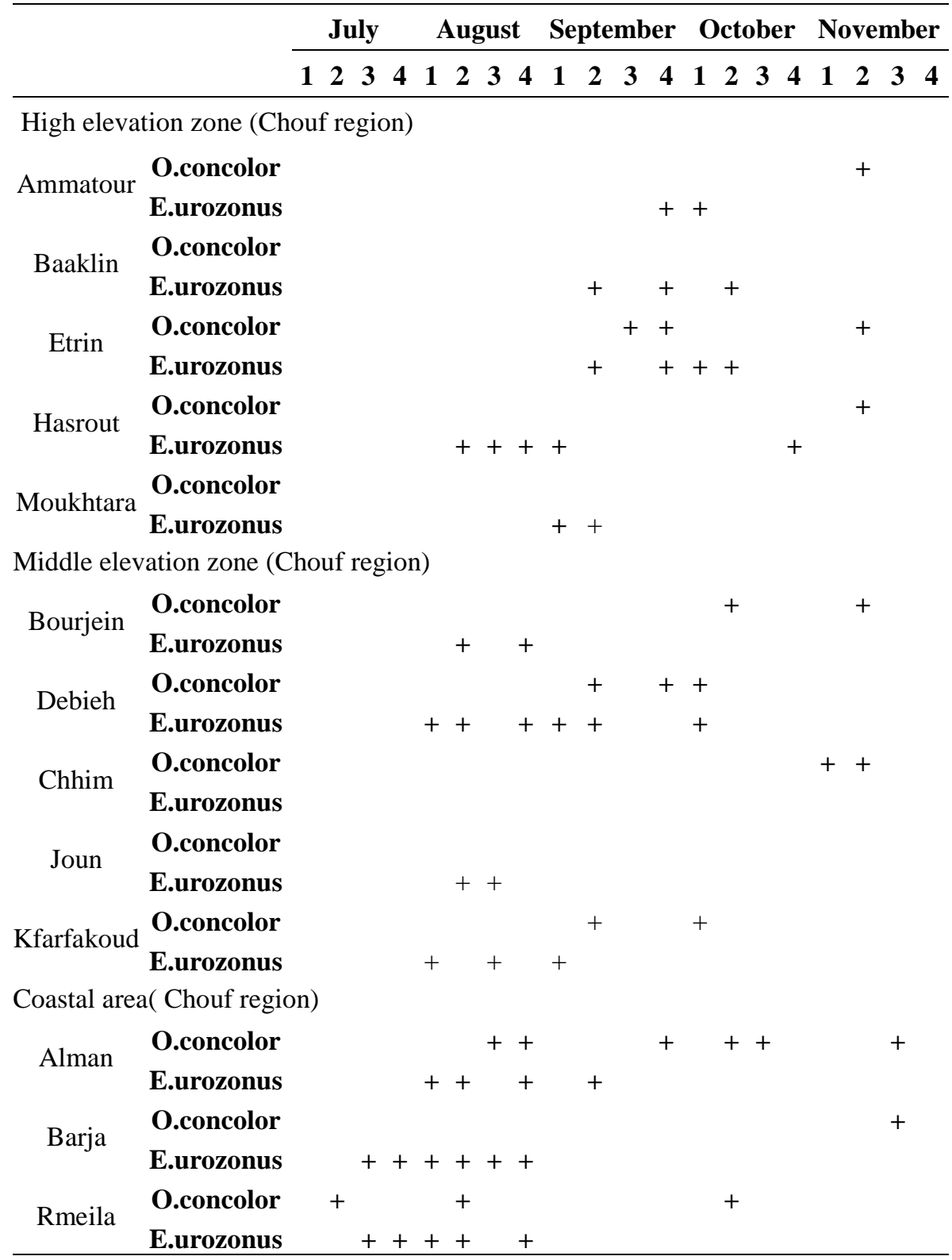

Saida- Jizzin region

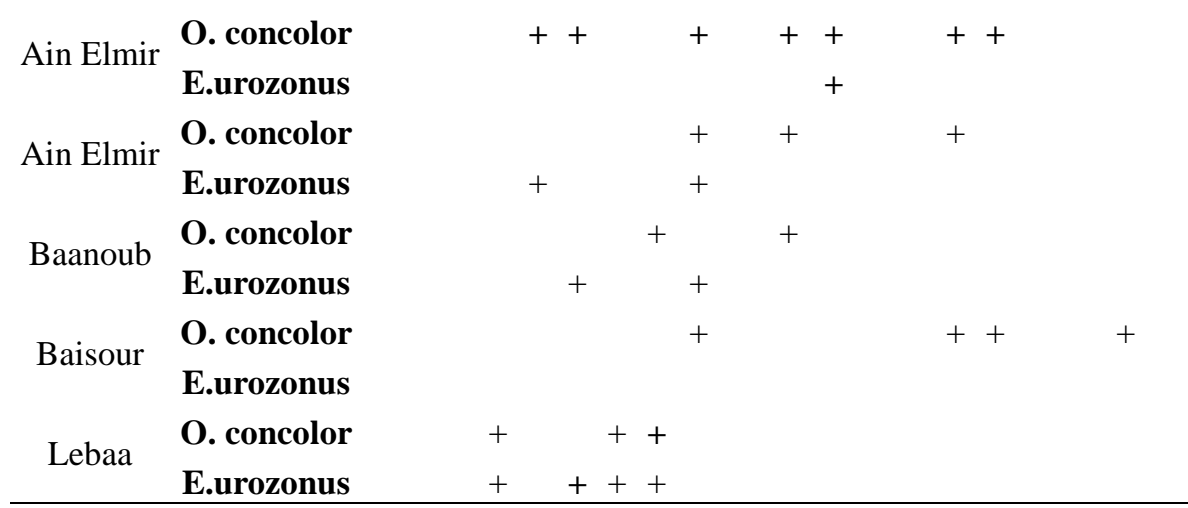


Table3 cont.

\begin{tabular}{|c|c|c|c|c|c|c|c|c|c|c|c|c|c|c|c|c|c|c|c|c|c|}
\hline & & \multicolumn{4}{|c|}{ July } & \multicolumn{4}{|c|}{ August } & \multicolumn{4}{|c|}{ September } & \multicolumn{4}{|c|}{ October } & \multicolumn{4}{|c|}{ November } \\
\hline & & 1 & 2 & 3 & 4 & 1 & 2 & 3 & 4 & 1 & 2 & 3 & 4 & 1 & 2 & 3 & 4 & 1 & 2 & 3 & 4 \\
\hline \multirow{2}{*}{ Mrah Hbas } & O. concolor & & & & & & + & & + & & & & & + & & & & & & + & \\
\hline & E.urozonus & & & & & & & & + & & & & + & & & & & & & & \\
\hline \multirow{2}{*}{ Salhieh } & O. concolor & & & & & & & & & + & & & + & & & & & & & & \\
\hline & E.urozonus & & & & & + & + & & + & & & & & & & & & & & & \\
\hline \multirow{2}{*}{ Sfarei } & O. concolor & & & & & & & & & & & & & & & & & & & & \\
\hline & E.urozonus & & & & & & & & & + & & & & & & & & & & & \\
\hline
\end{tabular}

Tyre region

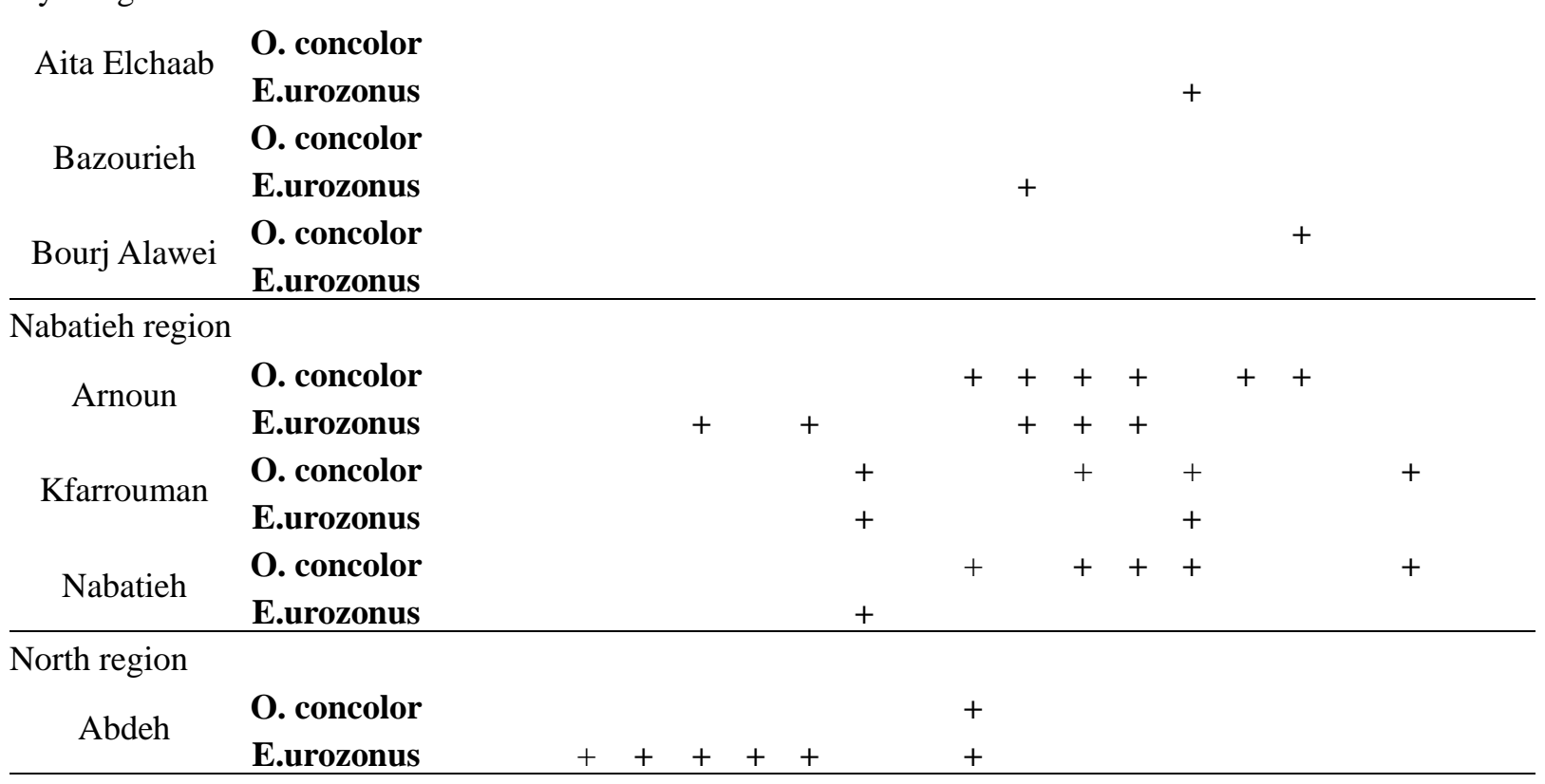

In addition to these parasitoids species , Chelonus blackburni (Hymenoptera,Braconidae) (Fig.2) was also isolated from different olive fruit samples. The inspection of these samples revealed the wide spread of this species in four regions( Chouf,Jizzin,Nabatieh and Tyre regions) .They were found in 15 orchards with a total number of 59 adults. This wasp is a solitary endoparasite of Lepidopterous larva (Dennis S.Hill,1994).Based on this fact we assume that olive moth (Prays oleae) which belongs to the Lepidoptera family was parasited by C.blackburni. Future studies should be conducted to prove this assumption. 


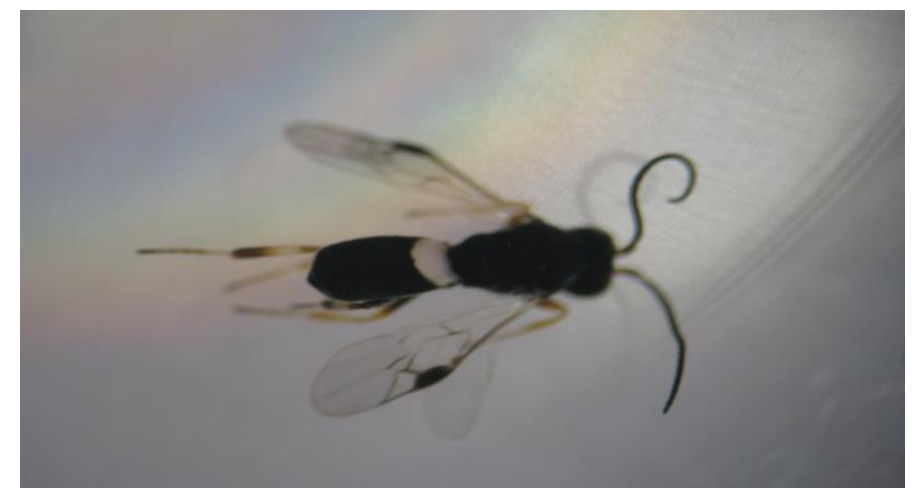

Figure2. Chelonus blackburni isolated from olive fruit samples.

2165 flies and 333 parasitoids were emerged from the 23096 collected olive fruits(Table4). The parasitism rate highly varied across all locations and ranged from $2.4 \%$ ( Ammatour) to $42 \%$ (Baanoub)(Table4). 


\section{Macrothink}

Journal of Agricultural Studies

ISSN 2166-0379

2018, Vol. 6, No. 1

Table4.Number of fruits, parasitoids ,emerged flies and parasitism rate recorded from four regions during 2014.

\begin{tabular}{|c|c|c|c|c|}
\hline Region & $\begin{array}{l}\text { No of } \\
\text { fruits }\end{array}$ & $\begin{array}{c}\text { No of flies } \\
\text { emerged }\end{array}$ & $\begin{array}{c}\text { No of parasitoids } \\
\text { emerged }\end{array}$ & $\begin{array}{c}\% \text { of } \\
\text { parasitism }\end{array}$ \\
\hline \multicolumn{5}{|l|}{ Chouf } \\
\hline \multicolumn{5}{|l|}{ High elevation zone } \\
\hline Ammatour MLC1 & 1017 & 80 & 2 & 2.4 \\
\hline Atrin MLC2 & 1372 & 74 & 12 & 14 \\
\hline Baaklin MLC3 & 1096 & 64 & 5 & 7.2 \\
\hline Hasrout MLC4 & 1215 & 151 & 36 & 19.3 \\
\hline Moukhtara MLC5 & 780 & 68 & 6 & 8.1 \\
\hline \multicolumn{5}{|l|}{ Middle elevation zone } \\
\hline Debieh MLC1 & 1215 & 143 & 24 & 14.4 \\
\hline Chhim MLC2 & 1145 & 87 & 2 & 2.2 \\
\hline Joun MLC3 & 200 & 11 & 2 & 15.4 \\
\hline Kfarfakoud MLC4 & 545 & 85 & 6 & 6.6 \\
\hline Bourjein MLC5 & 1024 & 121 & 11 & 8.3 \\
\hline \multicolumn{5}{|l|}{ Coastal zone } \\
\hline Aalman MLC1 & 958 & 71 & 17 & 19.3 \\
\hline Rmeila MLC2 & 768 & 99 & 13 & 11.6 \\
\hline Barja MLC3 & 1110 & 57 & 13 & 20.3 \\
\hline \multicolumn{5}{|l|}{ Saida-Jezzin } \\
\hline Ain Elmir1 SLC1 & 800 & 93 & 8 & 7.9 \\
\hline Ain Elmir2 SLC2 & 649 & 40 & 10 & 20 \\
\hline Baanoub SLC3 & 400 & 22 & 16 & 42.1 \\
\hline Baisour SLC4 & 765 & 66 & 10 & 13.2 \\
\hline Lebaa SLC5 & 1380 & 167 & 72 & 30.1 \\
\hline Mrah Hbas SLC6 & 762 & 92 & 7 & 7.1 \\
\hline Salhieh SLC7 & 675 & 42 & 10 & 19.2 \\
\hline Sfarei SLC8 & 630 & 14 & 1 & 6.7 \\
\hline \multicolumn{5}{|l|}{ Nabatieh } \\
\hline Arnoun NLC1 & 848 & 92 & 16 & 14.8 \\
\hline Haboush NLC2 & 949 & 116 & 9 & 7.2 \\
\hline Kfarrouman NLC3 & 993 & 117 & 10 & 7.9 \\
\hline \multicolumn{5}{|l|}{ Tyre } \\
\hline Bazourieh TLC1 & 600 & 59 & 2 & 3.3 \\
\hline Aita Elshaab TLC2 & 600 & 24 & 2 & 7.7 \\
\hline \multirow[t]{2}{*}{ Bourj Alawei TLC3 } & 600 & 110 & 11 & 9.1 \\
\hline & 23096 & 2165 & 333 & 13.3 \\
\hline
\end{tabular}




\section{Macrothink}

Parasitism rates in high and middle elevation zones of Chouf region were 10 and $8.9 \%$ respectively. In coastal area of Chouf region the P.rate reached 19\%. Nearly the same rate was observed in Saida-Jizzin region.The average parasitism rate of all locations was $13.2 \%$ (Table 4 ). These results agree with the results of Machelany and Abdelwali (1993) reporting in their works that parasitism by P.concolor reached peak levels of 12-16\%. One of reasons for this low parasitism rate may be a lack of synchronization between the life cycles of the parasitoid and fly (Kyriaki Varikou et al., 2014).Fruit infestation by olive fruit fly did not differ significantly among regions $\left(F(5,82)=0.71, p=0.618, \eta^{2}=0.04\right)$ as well as among locations $\left(\mathrm{F}(21,66)=0.57, p=0.913, \eta^{2}=0.15\right)$. A regression analysis was conducted to reveal the relationship between infestation and parasitism rate .The results showed that infestation did not predict significantly parasitism rate $, \beta=.968, t(85)=1.34, p=.1837, \eta^{2}=0.0093$.

\section{Conclusion}

The results of this study showed a widespread of O.concolor and E.urozonus in nearly all locations. The other isolated parasitoids were rare and restricted to specific locations. In addition to the B.oleae parasitoids that were already mentioned by Mechalany 1969, Tetrastachus sp. ,Pteromalus sp,and Bracon sp.are the new parasitoid species attacking B.oleae in Lebanon. Despite small number of parasitoids found in this study, many of the natural enemies of B.oleae may still be undiscovered in Lebanon .The low parasitism rate recorded in this study is insufficient to control olive fruit fly. Introduction and rearing of natural enemies along with other management tactics may enhance the control of olive fruit fly infestation.

\section{Acknowledgements}

The Managing Board of the Lebanese Agricultural Research Institute (LARI)-Lebanon is gratefully acknowledged for financial support. Special thanks are due to the administrative and technical staff of the Litani River Authority for their support. Technical staff of Lebaa station are thankful for their help.

\section{Reference}

Biliotti, E. (1961). Les problemes de systematique dans les recherches ecologiques sur les insectes entomophages Entomophaga 6:117-123.

Brnetic, D., \& Domazet, D. (1981). In: Biological control of olive fly (Dacus oleae Gmel.) by means of the sterile male technique and by O. concolor (O. concolor Szepl). [Online] Available:

http://mx.speciesfile.org/projects/8/public/public_content/show/13309?content_template_id= 88.

Cameron, E. (1941). The biology and post-embryonic development of Opius ilicis n. sp., a parasite of the holly leaf-miner (Phytomyza ilicis Curt.) Parasitology 33:151-169.

Daniela Marchini, et al. (2017). Bactrocera oleae reproductive biology: new evidence on wintering wild populations in olive groves of Tuscany (Italy) ,Bulletin of Insectology 70 (1): 121-128, ISSN 1721-8861. 


\section{Ml Macrothink}

Journal of Agricultural Studies

ISSN 2166-0379

2018, Vol. 6, No. 1

Fischer, M. (1963). Die Opiinae der aethiopischen Region (Hymenoptera: Braconidae) Beitraege zur Entomologie 13:194-221 662-747.

Iannotta, N., Belfiore, T., Noce M. E., Scalercio, S., \& Vizzarri, V. (2010). Comparison between attract and kill devices for B.oleae in an organic olive orchard:preliminary data,ISHS Acta horticulturae 873.

Kapaun, T., Nadel, H., Headrick, D., \& Vredevoe, L. (2009). Biology and parasitism rates of Pteromalus nr. myopitae (Hymenoptera: Pteromalidae), a newly discovered parasitoid of olive fruit fly Bactrocera oleae (Diptera: Tephritidae) in coastal California, Biological Control (2009), doi: 10.1016/j.biocontrol. 11.002.

Khouzami, M., Bassil, M., Fortunat, L., \& Hayek, A. (1996). Etude de la diversite biologique du Liban-Liste des especes",Projet GF/6105-92-72,Publication No 1.

Kim, A., Hoelmer, Alan, A., Kirk, Charles, H., Pickett, Kent, M., Daane, \& Marshall, W. Johnson. (2011). Prospects for improving biological control of olive fruit fly, Bactrocera oleae (Diptera: Tephritidae), with introduced parasitoids (Hymenoptera), Biocontrol Science and Technology $\cdot$ September.

Kyriaki VARIKOU, et al.(2014). Response of olive fruit fly Bactrocera oleae to various attractant combinations, in orchards of Crete", Bulletin of Insectology 67 (1): 109-114, ISSN 1721-8861.

LaSalle, J., \& Wharton, R. A. (2002). The identity and recognition of African Tetrastichusspecies (Hymenoptera:Eulophidae) associated with fruit flies (Diptera: Tephritidae), African Entomology Vol. 10, No. 2

Mechelany, E. (1969). Etude preliminaire sure Dacus oleae Gmel. Et son complexe parasitaire au Liban, Magon, Scientifique No.28 pp.17 pp. ref.8.

MoA,FAO, BCI (2010). Resultats globaux du module de recensement de l'agriculture, Project Observatoire Libanais de developpement agricole. [Online] Available:

http://www.fao.org/fileadmin/templates/ess/ess_test_folder/World_Census_Agriculture/Count ry_info_2010/Reports/Results_1/LBN_FIN_REP_FR_2010.pdf.

Monaco, R. (1978). Note sui parassiti del Dacus oleae Gmel. (Dipt.-Tephritidae) in Sud-Africa Atti del Congresso Nazionale Italiano di Entomologia 11:303-310.

Mustafa, T. M., \& Al-Zaghal, K. (1987). Frequency of Dacus oleae (Gmelin) immature stages and their parasites in seven olive varieties in Jordan Insect Science and its Application 8:165-169.

Tobias, V. I. ( 1977). The genus Opius Wesm. (Hymenoptera, Braconidae) as parasites of fruit flies (Diptera, Tephritidae) Entomologicheskoe Obozrenie 56:420-430

Zalom F. G., Van Steenwyk R. A., \& Burrack H. J. (2003). Olive fruit fly, Pest Notes, University of California ,publication 74112. 


\section{Macrothink}

Journal of Agricultural Studies

ISSN 2166-0379

\section{Copyright Disclaimer}

Copyright for this article is retained by the author(s), with first publication rights granted to the journal.

This is an open-access article distributed under the terms and conditions of the Creative Commons Attribution license (http://creativecommons.org/licenses/by/4.0/). 